\title{
Cytological study of body fluids for malignancy
}

\section{Original Research Article}

\author{
Saba H. ${ }^{1}$. Prakash C.J. ${ }^{2}$, Sharmila P.S. ${ }^{3}$, Vinitra. K. ${ }^{4}$ \\ ${ }^{1}$ Dr. Husain Saba, Resident, ${ }^{2}$ Dr. Prakash C.J., Professor, ${ }^{3}$ Dr. Sharmila P.S, Professor, ${ }^{4}$ Dr. Vinitra. K., Resident; all \\ authors are affiliated with Department of Pathology, Rajarajeshwari Medical College and Hospital Bengaluru, Karnataka, \\ India.
}

Corresponding Author: Dr. Husain Saba, Resident, Department of Pathology, Rajarajeshwari Medical College and Hospital Bengaluru, Karnataka, India. E-mail: sabahu1987@gmail.com

\begin{abstract}
Introduction: The effusion fluid analysis plays an important role in neoplastic conditions. The present study was undertaken to highlight the frequency of malignant cells in various body fluid. Materials and Methods: This observational study was performed for the period of one and half year. A total of 250 various type of body fluid samples received during the study period in the Department of Pathology, Rajarajeshwari Medical College and Hospital, Bengaluru, Karnataka were studied. Results: Most of the fluid samples belonged to males (59.20\%) and the male to female ratio was 1.45:1. The common age group of specimen received was 40 to 50 years $(21.20 \%)$. Most of the malignant lesions that is $53.85 \%$ and most of the suspicious of malignancy that is $66.67 \%$ were belonged to peritoneal fluid. Conclusions: Pleural fluids were the most common type of fluid received for analysis. Most of the fluid samples belonged to males. The frequency of malignancy in the population studies was $5.20 \%$ with adenocarcinoma being the common malignant lesion.
\end{abstract}

Keywords: Body fluids; Pleural fluid; Peritoneal fluid; CSF; Adenocarcinoma

\section{Introduction}

Body fluid cytology is an important diagnostic test for various malignant and benign conditions. Effusions can be caused by inflammatory, infectious, and benign; neoplastic or malignant; and primary or metastatic diseases. Such conditions in effusions may often have overlapping features and mimic one another both cytomorphologically and clinically, presenting diagnostic challenges [1].

The cytologic examination of body fluids is of distinct value in confirming or disapproving malignant metastatic tumors to the cavities [2]. The main serosal body cavity comprises pleural, peritoneal, pericardial, synovial and cerebrospinal fluids. The fluid cavities are lined by single layer of epithelium. Normally these cavities contain minimal fluid that is required for lubrication and protecting the underlying viscera. The dynamics of fluid accumulation is governed by starling's law, which states that fluid is accumulated when there is a decrease in the plasma colloidal pressure and increased capillary hydrostatic pressure. An effusion results in imbalance between fluid formation and removal [3].

Manuscript received: $8^{\text {th }}$ January 2019

Reviewed: $18^{\text {th }}$ January 2019

Author Corrected: $24^{\text {th }}$ January 2019

Accepted for Publication: $27^{\text {th }}$ January 2019
The cytological interpretation of individual cells that are exfoliated into these fluids is of paramount importance since they provide an insight into the diagnostic, prognostic and therapeutic aspect of various pathological processes in the body [4-6]. A high sensitivity and specificity of a cytological diagnosis of body fluids is presumably because the cell population present in the fluid sediment provides a more representative sample of a much larger surface area than that obtained by needle biopsy $[7,8]$.

Cytological examination of these fluids helps in diagnosing of both non neoplastic and neoplastic conditions. Most important is the recognition of a malignant pathology. But many other conditions such as inflammatory diseases, parasitic infestations, bacteria, fungi and viruses can also be identified [9]. Cytological evaluation of fluids is a relatively simple, rapid, inexpensive and less invasive tool having a high accuracy with low incidence of false positive diagnosis [10].

The purpose of present study is to evaluate the significance of fluid cytology for various pathological condition for malignancy in a tertiary care hospital and other pathological condition. Cytological study of body 
fluid is a complete diagnostic modality. First, it assists the clinician in formulating and pointing out the etiology of effusion and list of differential diagnoses, Secondly it allows one to follow the results of therapy and prognosis [11].

Need of Study: Study was undertaken as to date there is paucity of studies in literature on cytological study of body fluids and to date, no such study was undertaken in this institute. Most of the previous studies considered on or two type of fluid, this study comprises most common types of effusion collectively. Such study was lacking in this region.

Reason to publish: The findings prompted us to highlight the importance of study of body fluids for malignant cell and add information to the existing knowledge.

\section{Materials and Methods}

The present study was conducted in the Department of Pathology, Rajarajeshwari Medical College and Hospital, Bengaluru, Karnataka from November 2016 to April 2018.

Study design- The study design was a hospital based observational study.

Study period- The study was conducted for the period of one and half year from November 2016 to April 2018.

Source of data- All the body fluid samples received during the study period in the Department of Pathology, Rajarajeshwari Medical College and Hospital Bengaluru, Karnataka were studied.

Sample size- A total of 250 samples ware included in the study.

Sampling technique- Based on the previous three years hospital statistics that is, the average number fluid specimen received during past three years. The minimum sample size was determined as 100 .

However, during the study period that is, from November 2016 to April 2018 a total of 250 sample fluids of various types were received. Hence a total of 250 sample fluids ware studied.

\section{Selection Criteria}

Inclusion criteria- All effusion sample of pleural, peritoneal, pericardial cavities, CSF, Sputm, Synovial fluids. During the study period. Samples received from either sex of any age group.

\section{Original Research Article}

Exclusion criteria- Samples received from those patients who were already on treatment.

Ethical clearance- Prior to the commencement, the study was approved by the Ethical and Research Committee, Rajarajeshwari Medical College and Hospital Bengaluru, Karnataka.

Procedure- After receiving the fluid sample, details like type of fluid, clinical diagnosis, age and gender of the patient were noted and. Immediately the sample was centrifuged and the sediment smear were made. Cell blocks were made when feasible. Sediment smear were stained by Leishman stain, H\&E and pap stain.

Cell blocks were processed for H\&E stain. Gross description of fluid including volume, colour, turbidity, were noted and fluid was taken up for processing.

Cell count of the fluid was done in improved Naeubaur chamber. Direct smears and cytospin smears were prepared and stained with Haematoxylin and Eosin, and Leishman stain. Pap stain was done in case of presence of atypical cells. 100 cells were counted and differential count was expressed in percentage. Cytomorphology of the cells was studied and documented paying attention to cellular arrangement, cytoplasmic features and nuclear characteristics.

\section{Study variables}

The following variables were studied.

- Age and gender distribution pattern

- Type of fluid

- Clinical diagnosis

- Appearance of fluid

- Predominant cell type

- Cellular arrangement

- Malignant cells

- Final diagnosis

Statistical Analysis- The data obtained was coded and entered into Microsoft Excel Worksheet. The data was analysed using statistical software SPSS Version 20.0.

The categorical data was expressed as rates, ratios and proportions and continuous data was expressed as mean \pm standard deviation (SD).

Results-A total of 250 cases of serous effusions were examined cytoligically which included pleural, peritoneal, pericardial, synovial and CSF. 


\section{Original Research Article}

\section{Results}

Table-1: Distribution of Patients according to the gender.

\begin{tabular}{|c|c|c|}
\hline \multirow{2}{*}{ Gender } & \multicolumn{2}{|c|}{ Distribution (n= 250) } \\
\cline { 2 - 3 } & Number & Percentage \\
\hline Male & 148 & 59.20 \\
\hline Female & 102 & 40.80 \\
\hline Total & $\mathbf{2 5 0}$ & $\mathbf{1 0 0 . 0 0}$ \\
\hline
\end{tabular}

In the present study most of the fluid samples belonged to males $(59.20 \%)$ and $40.8 \%$ of the samples belonged to females. The male to female ratio was 1.45:1.

Table-2: Distribution of Patients according to the age and fluid type.

\begin{tabular}{|c|c|c|c|c|c|c|c|c|c|c|}
\hline \multirow{2}{*}{$\begin{array}{c}\text { Age Group } \\
\text { (Years) }\end{array}$} & \multicolumn{2}{|c|}{ CSF } & \multicolumn{2}{c|}{ Pericardial } & \multicolumn{2}{c|}{ Peritoneal } & \multicolumn{2}{c|}{ Pleural } & \multicolumn{2}{c|}{ Synovial } \\
\cline { 2 - 12 } & No. & \% & No. & $\%$ & No. & $\%$ & No. & $\%$ & No. & $\%$ \\
\hline 1 or Less & 31 & 57.41 & 0 & 0.00 & 3 & 3.85 & 0 & 0.00 & 0 & 0.00 \\
\hline 2 to 18 & 9 & 16.67 & 0 & 0.00 & 0 & 0.00 & 6 & 5.77 & 2 & 15.38 \\
\hline 19 to 30 & 3 & 5.56 & 0 & 0.00 & 7 & 8.97 & 29 & 27.88 & 1 & 7.69 \\
\hline 31 to 40 & 4 & 7.41 & 0 & 0.00 & 10 & 12.82 & 13 & 12.50 & 2 & 15.38 \\
\hline 41 to 50 & 4 & 7.41 & 1 & 100.00 & 23 & 29.49 & 23 & 22.12 & 2 & 15.38 \\
\hline 51 to 60 & 0 & 0.00 & 0 & 0.00 & 22 & 28.21 & 11 & 10.58 & 4 & 30.77 \\
\hline 61 to 70 & 0 & 0.00 & 0 & 0.00 & 12 & 15.38 & 16 & 15.38 & 1 & 7.69 \\
\hline 71 to 80 & 1 & 1.85 & 0 & 0.00 & 1 & 1.28 & 5 & 4.81 & 1 & 7.69 \\
\hline 81 to 90 & 2 & 3.70 & 0 & 0.00 & 0 & 0.00 & 1 & 0.96 & 0 & 0.00 \\
\hline Total & $\mathbf{5 4}$ & $\mathbf{2 1 . 6 0}$ & $\mathbf{1}$ & $\mathbf{0 . 4 0}$ & $\mathbf{7 8}$ & $\mathbf{3 1 . 2 0}$ & $\mathbf{1 0 4}$ & $\mathbf{4 1 . 6 0}$ & $\mathbf{1 3}$ & $\mathbf{5 . 2 0}$ \\
\hline
\end{tabular}

In this study CSF was the common type of fluid referred for analysis in those specimens which belonged to age $<1$ year. One sample of pericardial fluid was received which belonged to 41 to 50 years age group. Most Peritoneal fluid were referred from the patients who were aged between 41 to 50 years whereas pleural fluid in between 19 to 30 years. Most Synovial fluid were referred in patients who were aged 51 to 60 years $(30.77 \%)$.

Table-3: Distribution of Patients according to the type of fluid and type of lesion.

\begin{tabular}{|c|c|c|c|c|c|c|}
\hline \multirow{2}{*}{ Type of fluid } & \multicolumn{2}{|c|}{ Benign } & Suspicious of malignancy & \multicolumn{2}{c|}{ Malgnant } \\
\cline { 2 - 7 } & No. & $\%$ & No. & $\%$ & No. & 0.00 \\
\hline CSF & 54 & 23.08 & 0 & 0.00 & 0 & 0.00 \\
\hline Pericardial & 1 & 0.43 & 0 & 0.00 & 7 & 53.85 \\
\hline Peritoneal & 69 & 29.49 & 2 & 66.67 & 6 & 46.15 \\
\hline Pleural & 97 & 41.45 & 1 & 33.33 & 0.00 & 0 \\
\hline Synovial & 13 & 5.56 & 0 & $\mathbf{1 . 2 0}$ & $\mathbf{1 3}$ & $\mathbf{5 . 2 0}$ \\
\hline Total & $\mathbf{2 3 4}$ & $\mathbf{9 3 . 6 0}$ & $\mathbf{3}$ & & 0.00 \\
\hline
\end{tabular}

According to this study $41.45 \%$ of the benign lesions belonged to pleural fluid while $53.85 \%$ of the malignant lesions and $66.67 \%$ of the lesions suspected to be malignant were belonged to peritoneal fluid. 
Table-4: Distribution of patients according to the predominant cell type in fluid.

\begin{tabular}{|c|c|c|}
\hline \multirow{2}{*}{ Predominant cell type } & \multicolumn{2}{|c|}{ Distribution (n= 250) } \\
\cline { 2 - 3 } & Number & Percentage \\
\hline Lymphocytes & 172 & 68.80 \\
\hline Neutrophils & 42 & 16.80 \\
\hline Mesothelial cells & 10 & 4.00 \\
\hline Atypical cells & 8 & 3.20 \\
\hline No predominant cell type & 18 & 7.20 \\
\hline Total & $\mathbf{2 5 0}$ & $\mathbf{1 0 0 . 0 0}$ \\
\hline
\end{tabular}

In this study majority of the fluids (68.8\%) had lymphocytes as a predominant cell type followed by neutrophils (16.8\%). Smears showing predominance of lymphocytes point towards benign lesions whereas predominance of neutrophils in sheets and clusters point towards acute inflammatory process.

Table-5: Distribution of patients according to the malignant lesions.

\begin{tabular}{|c|c|c|}
\hline \multirow{2}{*}{ Malignant lesions } & \multicolumn{2}{|c|}{ Distribution (n = 13 ) } \\
\cline { 2 - 3 } & Number & Percentage \\
\hline Adenocarcinoma & 5 & 38.46 \\
\hline Malignant Primary Ca ovary & 4 & 30.77 \\
\hline Malignant Primary Breast Ca & 2 & 15.38 \\
\hline Ca of unknown origin & 2 & 15.38 \\
\hline Total & $\mathbf{1 3}$ & $\mathbf{1 0 0 . 0 0}$ \\
\hline
\end{tabular}

In this study adenocarcinoma was the common diagnosis noted in $38.46 \%$ of the patients with malignant lesions. The other lesions are as shown in table no. 05

\section{Discussion}

Main body fluids like pleural, peritoneal, pericardial, cerebrospinal fluid (CSF) and synovial fluid are normally present within respective body cavities in minimal quantities with their constituents in specific proportions. These fluids during a disease process undergo qualitative and quantitative changes $[6,8,12]$. Cytological examination of body fluid is of distinct value in confirming or disapproving malignant metastatic tumors to the cavities. Since mesothelial and synovial tumors are rare, this method is useful to detect metastatic malignant cells to the body cavities. The method is more of prognostic value rather than for the early detection or prevention of further tumor growth [2].

Cytological examination of these fluids helps in diagnosing of both non-neoplastic and neoplastic conditions. Most important is the recognition of a malignant pathology. But many other conditions such as inflammatory diseases, parasitic infestations, bacteria, fungi and viruses can also be identified [9]. The advantages of this method are that it is a relatively simple, rapid, inexpensive and less invasive tool having a high accuracy with low incidence of false positive diagnosis [10]. The present study was an attempt to highlight the frequency of malignant cells in various body fluids.

This observational study was undertaken for the period of one and half year. A total of 250 various types of body fluid samples received in the Department of Pathology, Rajarajeshwari Medical College and Hospital, Bengaluru, Karnataka were studied for the presence of malignant cells.

In the present study most of the fluid samples belonged to males $(59.20 \%)$ and $40.8 \%$ of the samples belonged to females. The male to female ratio was 1.45:1 suggesting male preponderance. These findings were comparable with a similar study by Mahajan S. et al [13] (2017) from Moradabad, India where $58.66 \%$ of the sample belonged to males which was sharply in agreement with the present study. Another study by Shobha SN et al [14]. (2017) from Mandya, Karnataka also reported male preponderance with $62 \%$ of the males. The sex distribution pattern observed in the present study was similar to the studies by Mahajan S. et al. [13], Shobha SN et al. [14]. In contrast to the observations to the present study, a study by Khatib WM et al [15] reported almost equal incidence with males 208 (50.24\%) cases being slightly more than female 206 (49.75\%) cases. 


\section{Original Research Article}

In this study the specimens collected belonged right from newborn to individuals as old as 90 years. Based on the decades, the common age group of specimen received was 40 to 50 years $(21.20 \%)$ followed by 19 to 30 year (16\%). However, $20.4 \%$ of the specimen belonged to paediatric age group and $16 \%$ of the specimens were received from elderly individuals. The mean age was $38.51 \pm 22.49$ years. The mean age of the study population suggests that most of the specimens belonged to middle aged individuals and children.

The mean age observed in the present study was comparable with a recent study by Khatib WM et al [15] who reported that, majority of the cases were in 40-50 age group with mean age of presentation being 46.6 years. Our study was also in concordance with studies done by Sulbha et al [12], Joshi et al [4] and Pradhan et al [16]. In contrast to these observations, Shobha SN et al [14] reported that, though, maximum number of samples was in the age group of 51-60 Years. Least number of samples was in age group 1-10 Years suggesting less number of children are affected compared to older ones while in the present study most of the samples belonged to elderly (age 60 years; $16 \%$ ) and children (age 18 years $20.4 \%)$.

In the present study with regard to clinical characteristics, there was wide variation in the clinical diagnosis. However, the common clinical diagnosis was tuberculosis $(18.80 \%)$ followed by liver disease $(16 \%)$ and pneumonia $(13.20 \%)$. The clinical diagnosis noted in the present study slightly differed from a study by Deshpande AK. et al [2] from Hyderabad where, authors encounter 12 cases (8\%) of tuberculous effusions, 8 (66.6\%) from pleural and 4(33.33\%) from peritoneal cavities.

In the present study, most of the specimens received were pleural fluids (41.6\%) being the common type followed by peritoneal fluid (31.20\%), CSF (21.60\%). Few samples of Synovial $(5.20 \%)$ and, pericardial fluid $(0.40 \%)$ were received. In a study by Sharma M. et al [6] from Jammu, pleural fluid was received in $45.6 \%$ of the patient a finding consistent with the present study. Ayyagari Sudha et al [17] in a study from Hyderabad received pleural specimen fluid 49\% followed by peritoneal fluid $41.39 \%$, which is similar to our observations. In contrast to these observations, a study by Gupta R. et al [18] (2016) who reported that, peritoneal fluid was the commonest fluid received for evaluation in their study (49.7\%). Another study by Sulbha VS et al [12] also reported that, peritoneal fluid was the commonest fluid received for the analysis (45.1\%). Similarly, Khatib WM et al [15] reported peritoneal fluid was the most frequently encountered effusion with 189 (45.65\%) cases followed by pleural fluid with 138 (33.34\%) cases. The disparity observed between the frequency of type fluid in the present study and other studies may be attributed to the common clinical diagnosis of tuberculosis and pneumonia in the present study and varied sample size as well as selection criterion in the different studies.

Further, pleural fluid was almost common fluid referred among males (42.57\%) and females (40.20\%). But, CSF was the common type of fluid referred for analysis in those specimens which belonged to age $<1$ year. One sample of pericardial fluid was received which belonged to 41 to 50 years age group. Peritoneal fluid was the most common fluid referred from the patients who were aged between 41 to 50 years whereas pleural fluid in the age group of 19 to 30 years. Synovial fluid was referred in patients who were aged 50 to 60 years (30.77\%). These findings were in agreement with the study of Khatib WM et al [15] who reported that, across both sexes, pleural fluid was the most common fluid to be tapped followed by peritoneal fluid. Another study by Sharma M. et al [6] from Jammu also reported that, pleural fluid was the most common fluid to be referred for the evaluation.

In the present study with regard to fluid characteristics, most of the fluid specimen $(26 \%)$ of had straw colour, majority of the fluids $(60.8 \%)$ had lymphocytes as a predominant cell type followed by neutrophils $(16.8 \%)$ and majority of the patients had single cellular arrangement in fluid. However these findings cannot be compared with other studies due to lack of similar data in the literature. Neutrophils in clusters and sheet admixed with mesothelial cell and degenerating cells point towards acute inflammatory process. Recognizing inflammation is important for early treatment. Sometimes the presence of overwhelming population of neutrophils masking the other atypical cells may lead to suspicious diagnosis in benign conditions also.

In this study majority of the fluid specimens that is $93.6 \%$ of the specimens were diagnosed as benign lesions while diagnosis of malignant lesions was noted in $5.2 \%$ of the fluid specimens and $1.2 \%$ of the fluid specimens were diagnosed as suspicious of malignancy. Hence the frequency of malignancy in this study was $5.20 \%$. The rate of malignancy observed in the present study is to similar study by Gupta R. et al [18] also reported 10 neoplastic lesions out of 185 fluid samples studied. Khatib WM et al [15] who reported that, $7.48 \%$ of the cases were malignant in their study which was 


\section{Original Research Article}

slightly high compared to the present study. Samar A. et al [10] reported rate of malignancy as $10.9 \%$ which was very high compared to the present study. Sharma M. et al [6] (reported rate of malignancy as 5.4\% which was consistent with the present study. Kol PC et al [19] of 180 cases, showed malignant effusions in $30(16.66 \%)$ cases which was very high compared to the present study. Sulbha VS.et al [12] reported 04 neoplastic lesions out of 174 cases studied that is, $2.29 \%$ which was very low compared to the present study.

Table-6: Comparison of our study results with similar studies.

\begin{tabular}{|c|c|c|c|c|}
\hline Author & Year & $\begin{array}{c}\text { Malignant lesions } \\
\mathbf{( \% )}\end{array}$ & Benign lesion & $\begin{array}{c}\text { Suspicious of } \\
\text { malignancy (\%) }\end{array}$ \\
\hline Kol PC et al. [19] & 2016 & $16.66 \%$ & $77.77 \%$ & $5.50 \%$ \\
\hline Gupta R. et al. [18] & 2016 & $5.40 \%$ & $94.59 \%$ & - \\
\hline Khatib WM et al. [15] & 2016 & $7.48 \%$ & $83.09 \%$ & - \\
\hline El Sheikh SA. et al. [10] & 2012 & $10.90 \%$ & $89.10 \%$ & - \\
\hline Sharma M. et al. [6] & 2017 & $5.40 \%$ & $90.40 \%$ & $4.20 \%$ \\
\hline Sulbha YS.et al. [12] & 2015 & $2.59 \%$ & $97.40 \%$ & - \\
\hline Present study & 2018 & $5.20 \%$ & $93.60 \%$ & $1.20 \%$ \\
\hline
\end{tabular}

In this study adenocarcinoma was the common diagnosis noted in five fluid specimens out of 13 that is, $38.46 \%$ of the patients with malignant lesions. The next common lesion was malignancy with primary carcinoma ovary in 4 fluid specimens out of $13(30.77 \%)$ followed by malignancy with primary carcinoma of breast with metastasis and Ca of unknown origin that 2 each out of 13 fluid specimen (15.38\%). Hence adenocarcinoma was the common malignant lesion. Adenocarcinoma was the commonest type of malignancy in the study by Shulbha VS et al [12]. Jha R et al [20] in their study found that adenocarcinoma as most common malignancy. Sears and Hajdu [21] in their study also showed similar findings. Another study by Mahajan S. et al [13] out of all 15 positive cases of malignancy maximum number $(n=12)$ of cases are found to be adenocarcinoma of lung which was high compared to the present study. However in the present study out of five adenocarcinomas, one sample was diagnosed as adenocarcinoma of lung.

In the present study, the rate of malignancy was high in females (69.23\%) and it was common in the age group of 61 to 70 years (38.46\%). In contrast to these observations, EI-Sheikh SA et al [10] (2012) reported significantly higher number of malignant lesions in males ( $52.6 \%$ vs $47.4 \%$; $\mathrm{p}=0.04)$ than females.

Table-7: Comparison of male to female ratio in malignancy.

\begin{tabular}{|c|c|c|}
\hline Author & Year & Male to female ratio \\
\hline El-Sheikh SA et al 10 & 2012 & $1.1: 1$ \\
\hline Present study & 2018 & $1: 2.25$ \\
\hline
\end{tabular}

In the present study out of 13 malignant lesions, maximum malignant lesions were noted in peritoneal fluid samples (53.85\%) followed by pleural fluid samples (46.15\%). While no malignant lesions were diagnosed in CSF, Pericardial and synovial fluid samples. These findings are in agreement with the study of Sharma M. et al [6] and Kol PC et al [19]. In another study by Khatib WM et al [15], majority of the malignancies were found in the peritoneal fluid which was consistent with the present study. Other studies by Sulbha VS et al [12] and Wong JW et al [22] also found that pleural fluid showed highest proportion of positivity for malignant cells. On the contrary, earlier, Wong JW et al [22], pleural fluid was found to have the highest positivity for malignant cells amongst all fluid.

Overall, the present study showed that, fluid cytology is very useful in classifying benign conditions, further it plays a very useful role in rapid diagnosis of malignant effusions. Fluid cytology although not a substitute for conventional histopathology but as complementary to it and is useful in categorizing benign conditions as well as in the diagnosis of malignant conditions. The frequency of malignancy in the population studies was $5.20 \%$ with adenocarcinoma being the common malignant lesion. Maximum malignant lesions were noted in peritoneal fluid samples followed by pleural fluid samples while no malignant lesions were diagnosed in CSF, pericardial and synovial fluid samples. Furthermore, the rate of malignancy was high in females and is common in the-age group of 61 to 70 years. 


\section{Original Research Article}

However these findings cannot be generalized and need further validation due to potential limitations of this study viz. single centre study involving relatively smaller sample size. Hence further multicentric studies involving large sample size may provide the true facts about the malignant lesions diagnosed during the fluid analysis.

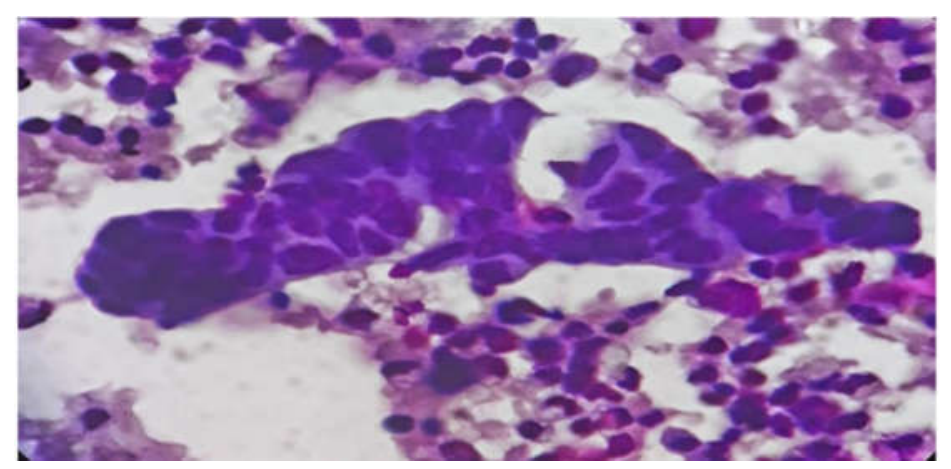

Photograph-1: Conventional smear: 100x (Oil immersion): Maligant cells in peritioneal fluid

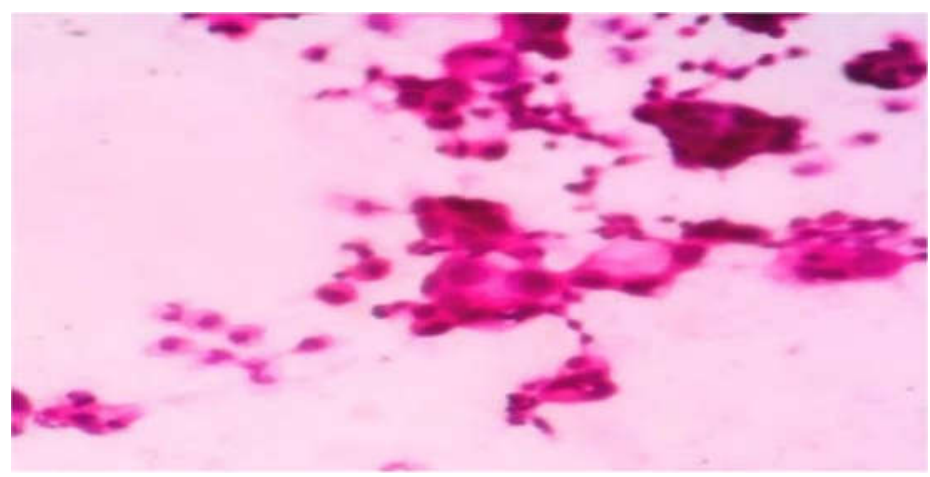

Photograph-2: Conventional smear: 40x: Maligant cells in acinar pattern having intracellular mucin vacuoles, background shows inflammatory cells, Perioneal effusion

\section{Conclusion}

Based on the findings of this study it may be concluded that, pleural fluids was the most common type of fluid received for analysis. Most' of the fluid samples belonged to males. The frequency of malignancy in the population studies was $5.20 \%$ with adenocarcinoma being the common malignant lesion.

Maximum malignant lesions were noted in peritoneal fluid samples followed by pleural fluid samples while no malignancy was diagnosed in CSF, pericardial and synovial fluid samples. Furthermore, the rate of malignancy was high in females and is common in the age group of 61 to 70 years. Thus, fluid cytology is an important diagnostic tool and can be applied as first line diagnostic procedure as it is simple, relatively painless, cost effective less time consuming and gives quick results. Fluid cytology is useful complementary diagnosis for categorizing benign as well as malignant conditions.

Prakash C.J. is guide of the work done has immensely helped to complete the project work. Sharmila P.S,
Head of Department and source of inspiration and was resource person during the study period. Vinitra. K. resident helped in preparing the manuscript.

Findings: Nil; Conflict of Interest: None initiated Permission from IRB: Yes

\section{References}

1. Tabatabai ZL, Nayar R, Souers RJ, et al. Performance Characteristics of Body Fluid Cytology Analysis of 344380 Responses From the College of American Pathologists Interlaboratory Comparison Program in Nongynecologic Cytopathology. Arch Pathol Lab Med. 2018 Jan; 142 (1):53-58. doi: 10.5858/ arpa. 2016-0509-CP. Epub 2017 Oct 19.

2. Deshpande AK, Bhaskaran S. Comparative Study of Body Fluid Cytology using Cytospin-II and Ordinary Centrifuge. JEMDS 2015; 4(40): 6904-10.

3. Nguyen G.K., Essentials of fluid cytology, Canada: Library and Archives 2009 
4. Joshi A, Mahajan N, Karmarkar PJ, Mahore SD. Diagnostic utility of various techniques used in body fluid cytology. IOSR- JDMS 2014; 13(1): 13-8.

5. Poorana PP. Cytological analysis of body fluids in conventional smear and cell block technique study of 120 cases. Int. J Pharm Bio Sci 2015; 6(4),609-15.

6. Sharma M, Sharma A, Khajuria A, Gandhi S. Evaluation of Pathological Body Fluids: An Important Diagnostic Aid India Journal of Basic and Applied Medical Research - Diagnostic research social issue, March 2017;6(2):18-24.

7. Cibas ES. Pleural pericardial and peritoneal fluids. In: Cibas ES and Ducatman BS editors. Cytology: Diagnostic principles and clincal correlate. 3rd ed. Philadelphia : Elsevier : 2009 p. 129-53.

8. Chakrabarti PR, Kiyawat P, Verma A, Agrawal P., Dosi S. Dixit M. Cytological evaluation of serous body fluids: a two year experience in tertiary care centre from the central India Int. J. Cur Res Rev 2015; (17):1-6.

9. Naylor B. Pleural peritoneal and pericardial effusions. In: Bibbo M, Wilbur DC. eds. Comprehensive Cytopathology. 3rd ed., Philadelphia: Elsevier saunders: 2008 p. 515-77.

10. El-Sheikh SA. The Diagnostic Value of Pleural Fluid Cytology in Benign and Malignant Pleural Effusions. Med J Cairo Univ. 2012 ; 80(2): 95-103.

11. Bhanvadia VM, Santwani PM, Vachhani JH. Analysis of diagnostic value of cytological smear method versus cell block method in body fluid cytology: study of 150 cases. Ethiop J Health Sci. 2014 Apr;24(2):125-31.

12. Sulbha VS, Dayananda BS. Cytology of body fluids- an aid to primary diagnosis. Indian $\mathrm{J}$ of Pathol Oncol 2015; 2(2):81-3.

13. Mahajan S, Awasthi S, Dutta s. Cytological Diagnosis of Serous Effusions by Using Comparative

\section{Original Research Article}

Approach of Routine Staining and Cytospin Technique Rnn Int. Med. Den Res 2017; 3(4) ; PT 46-51.

14. Shobha SN, Rajashekar YR. Diagnostic approach to pleural effusions. Indian Journal of Pathology and Oncology June 2017;4(2):199-202.

15. Khatib WM, Patel PM. Demde RB, Aher VC. Exfoliative cytology of body fluids: an analysis. Asian Pac J Health Sci, 2016; 3(4): 117-9.

16. Pradhan SB, Pradhan B, Dali S. Cytology of body fluids from different sites: an approach for early diagnosis of malignancy. JNMA J Nepal Med Assoc. 2006 Oct-Dec;45(164):353-6.

17. Ayyagari Sudha, Padmaja Korti, Shailaja Prabhala,, Ashok Kumar Deshpanday. Cytological analysis of body fluids with an emphasis on malignant effusions. Indian journal of pathology and oncology, March 2018; 5(1): 106-111

18 Gupta R, Dewan D, Raina R, Gupta M. Exfoliative, cytology of body fluids: a study from provincial hospital of Jammu region, India. Int J Res Med Sci 2016; 4:1016-9.

19. Kol PC, Singh SK, Singh UR. Diagnostic Value of Exfoliative cytology Evaluation of Serous Effusions. International J Sci Res 2016 ; 5(2) : 244-6.

20. Jha R, Shrestha HG, Sayami G, et al. Study of effusion cytology in patients with simultaneous malignancy and ascites. Kathmandu Univ Med J (KUMJ). 2006 Oct-Dec;4(4):483-7.

21. Sears D, Hajdu SI. The cytologic diagnosis of malignant neoplasms in pleural and peritoneal effusions. Acta Cytol. 1987 Mar-Apr;31(2):85-97.

22. Wong JW, Pitlik D, Abdul-Karim FW. Cytology of pleural, peritoneal and pericardial fluids in children. A 40-year summary. Acta Cytol. 1997 Mar-Apr; 41 (2): 467-73. DOI:10.1159/000332540

\section{How to cite this article?}

Saba H, Prakash C.J, Sharmila P.S, Vinitra. K. Cytological study of body fluids for malignancy. Trop J Path Micro 2019;5(1):43-50.doi:10.17511/jopm.2019.i01.08. 